\title{
Alcohol, Condom Use and Sexu- ally Transmitted Infections: A Letter from Russia
}

Keywords: Alcohol abuse; Health care; Contraception; Sexually transmitted infections

\begin{abstract}
The abortion rate in the former Soviet Union was reported to be the world highest, being caused not only by the insufficient availability of modern contraception but also by irresponsible behavior. The alcohol overconsumption has been perceived as a contributing factor. The social background and cause-effect relationships between the alcohol abuse, heavy binge drinking and certain behavioral stereotypes are discussed here based on the literature and our observations since the 1970s. The conclusion is that the use of condoms is dependent on individual traits and a level of social development; however, alcohol consumption at sexual encounters and heavy binge drinking are risk factors for the non-use of condoms and other irresponsible behaviors potentially contributing to the spread of sexually transmitted infections.
\end{abstract}

\section{Case 1}

A son of a higher officer awarded himself a next "military rank" every time he was infected with Gonorrhea (Gn). In this way he became a generalissimo, which illustrates irresponsibility - the patient was in fact proud of his "career". The patient was one of the leaders of a drinking company that involved adolescents into alcohol consumption, teenage girls into sexual contacts, etc. The patient and his companions treated themselves with intramuscular injections of Bicillin (Benzathin-Benzylpenicillin). Retrospectively it is unclear when it was a fresh infection or exacerbation: the case was reported to the authorities after years of the patient's activities. This case demonstrates that the society and authorities factually permitted the spread of Sexually Transmitted Infections (STI), in particular, by people from higher social classes. The same company applied for induction of abortions intramuscular injections of oil solution of Hexestrol (named Synoestrol in Russia), which was broadly used for that purpose [1].

\section{Case 2}

A female student residing in a students' dormitory was infected with $\mathrm{Gn}$. It should be commented that female students were sometimes manipulated towards sexual contacts by certain administrators and professors whereas alcohol consumption played its role [2,3]. First time she had not noticed any symptoms. Shortly thereafter she was admitted to a gynecology department with the diagnosis of adnexitis. In the meantime, her partner developed acute urethritis with an abundant purulent discharge. An acquainted physician prescribed them an antibiotic of foreign production that was not available at the hospital. The patient took it in addition to the hospital medication. The recovery was complete. Gn was not diagnosed at the hospital, which permitted the couple to avoid some of the procedures described
Journal of

\section{Addiction \& Prevention}

\author{
Sergei V. Jargin* \\ Department of Pathology, People's Friendship University of Russia, \\ Russia \\ *Address for Correspondence \\ Sergei V. Jargin, Department of Pathology, People's Friendship \\ University of Russia, Russian Federation, University of Russia, \\ Clementovski per 6-82, 115184 Moscow, Russia, Tel: +7 495 \\ 9516788; E-mail: sjargin@mail.ru \\ Submission: September 09, 2018 \\ Accepted: September 20, 2018 \\ Published: September 26, 2018 \\ Copyright: () 2018 Jargin SV. This is an open access article distributed \\ under the Creative Commons Attribution License, which permits \\ unrestricted use, distribution, and reproduction in any medium, provided \\ the original work is properly cited.
}

in $[4,5]$. The methods of topical treatment and provocation, inherited from the pre-antibiotic era, not mentioned by internationally used textbooks, reviews and recommendations by the World Health Organization (WHO), have been used until recently in the former Soviet Union (SU) [4,5]. High-risk groups knew about lengthy and unpleasant treatments applied at the governmental prevention and treatment centers (so-called dermatovenereological dispensaries) and avoided them. Responsible individuals administered themselves regular courses of antibiotics, but others treated themselves inadequately and continued spreading STI.

\section{Background}

The abortion rate in the former SU has been the highest in the world caused not only by the insufficient availability of modern contraception and poor quality of condoms but also by certain behavioral stereotypes [6]. An unofficial directive aimed at the birth rate enhancement has apparently played a role [7]. Besides, the alcohol overconsumption was perceived as a factor contributing to the nonuse of condoms. Fortunately, the abortion rate has been decreasing in the former SU since the 1980s $[6,8]$, the alcohol consumption and heavy binge drinking tending to decrease as well $[9,10]$.

\section{Focused Review}

The alcohol intake was reported to be associated with a disinhibitory behavioral impact and diminished perception of risk, increasing the likelihood that individuals put themselves at risk of STI by engaging in unsafe sexual practices e.g. unprotected intercourse, multiple and concurrent sexual partners $[11,12]$. In younger and less experienced people e.g. students, problematic use of alcohol is associated with novelty, sensation and popularity seeking and hence with risky behaviors [13]. According to a meta-analysis, the hazardous alcohol use has been associated with risky sexual behaviors: multiple partners, inconsistent condom use etc. [12]. In particular, the alcohol misuse has been associated with behaviors that place women at a greater risk for STI/HIV [14]. Among HIV-infected people, an association between the alcohol abuse or dependence with sex-risk behaviors, including the inconsistent condom use, was found [15]. It 
is not surprising that links between alcohol involvement (frequency of alcohol intake, symptoms of alcohol disorder) and STI risk have been demonstrated [16].

The association between alcohol and high-risk behaviors is explainable within the scope of the alcohol myopia theory, according to which, alcohol reduces the cognitive capacity and causes people to focus on the cues that are most salient in the environment. Less salient cues (e.g. possibility that the partner may be infected with STI) require additional cognitive resources to process being less likely to be acted upon by an inebriated individual [17]. According to a survey performed in adolescents, "ever used alcohol before sex" was associated with "ever been pregnant" [18]. Moreover, some studies indicate that sexually aggressive acts often do not involve condom use, while rapist alcohol consumption and condom non-use correlated [19]. Conversely, the sex without coercion was associated with a more frequent condom use [20]. The correlation between victimization and sexual risk-related behaviors is well established, the supposed mechanism being weakened assertiveness [21].

Several experimental studies have demonstrated that alcohol intoxication interferes with the ability to evaluate consequences of high-risk situations [22-25]. In accordance with the myopia theory, alcohol was shown to interfere with the recognition of ambiguous risk cues, whereas clear cues continued to be recognized. For example, a moderate dose of alcohol impaired the intoxicated women's perception of ambiguous sexual assault risk cues but did not diminish perception of clear sexual assault risks [25-27]. It should be commented that in the experimental studies [22-25], alcohol doses designated as "high" (4-5 drinks) were moderate according to ex-Soviet standards. At the doses e.g. 0.75-1,5l of fortified wine or $\geq 250 \mathrm{ml}$ of vodka accompanied by beer the perception of risks may decrease considerably [28].

There is an opinion that people who use condoms being sober would use them also when they are drinking, while those who fail to use condoms when drinking would fail to use them also when sober [29]. However, empirical exceptions from this rule are recognized [17]. Undoubtedly, sexual behaviors largely depend on individual traits; but heavy binge drinking and alcohol consumption at sexual encounters are largely considered to be risk factors for the non-use of condoms [30-35], which agrees with our observations in the former SU since the 1970.

Another issue is the dependence of sexual behaviors on the past experience of alcohol overconsumption. We have found in the literature no data on correlations between the duration of alcohol abuse, age, use of condoms and the incidence of STI; therefore the following considerations are partly theoretic, based on circumstantial evidence and observations. Multivariate analyses indicated that a higher weekly alcohol use increased women's perceived risk of an intercourse as a result of a man's authority or coercion; i.e. women who were heavy drinkers perceived themselves at a higher risk for sexual victimization. However, even when women recognize that alcohol use increases the risk for assault, they may not take steps to reduce the risk or to reduce their alcohol consumption [36]. For binge drinkers in general, stronger appraisals of the positive consequences for having an intercourse while intoxicated predicted lower STIprotective self-efficacy [37]. According to the author's observations, some individuals having alcohol dependence and increased alcohol tolerance preserved a high level of risk perception and behavioral skills in conditions of alcohol intoxication. However, personality changes as a result of a prolonged alcohol abuse and heavy binge drinking would sooner or later interfere with the risk perception and behavioral skills. The non-use of condoms is apparently favored by the personality changes developing after a prolonged alcohol abuse, such as cognitive impairment, deficits in the frontal inhibitory control and working memory $[38,39]$ i.e. symptoms more or less compatible with the beginning alcohol-related dementia, overlapping with such entities as the frontal lobe syndrome and organic personality disorder. Among manifestations of these conditions are a poorly planned irresponsible behavior and impulsivity i.e. inability to forego small, immediate rewards for larger, delayed rewards [40]. The damage of neural structures can be caused not only by the prolonged alcohol overconsumption per se but also by poor quality of alcoholic beverages i.e. other substances than ethanol $[28,41]$.

Finally, the use of condoms depends on the level of social development. All studies, known to us, not unequivocally confirming the association between alcohol drinking and non-use of condoms, were performed in more developed countries including Russia [17,42-50]; while those from less developed and newly industrialized countries do generally confirm such association [51-59]. In the U.S. indicators of the alcohol consumption were stronger predictors of an inconsistent condom use in African Americans than in Whites [60]. Low education levels were associated with risky sexual behaviors (not using condoms, drunk at last sexual act, $\geq 3$ sexual partners in the past year) in young indigenous Australians [61]. It can be reasonably assumed that, along with the social and cultural development, the attitude towards contraception tends to become more responsible, distracting factors such as alcohol gradually losing power. Accordingly, less acculturated men have been found to drink more heavily, being more likely to engage in risky sexual behavior than more acculturated ones [62]. The literature cited in the systematic review and metaanalysis is compatible with this concept [12]. However, international migrations may confound this scheme. In parallel with the cultural development and education, the promiscuity among adolescents tends to decrease e.g. in Southern Africa [18], although such data are difficult to generalize on a global scale.

\section{Conclusion}

According to the literature and our observations, the heavy binge drinking and alcohol consumption at sexual encounters are risk factors for the non-use of condoms and hence of the STI/HIV. Moreover, the chronic alcohol abuse and heavy binge drinking are associated with personality changes potentially conductive to the irresponsible behavior including the non-use of condoms. The role of the quality of alcoholic beverages i.e. chemical substances other than ethanol should be investigated $[28,41]$. The mechanisms discussed above probably contributed to the growing HIV prevalence in the former SU [63]. Among predisposing social factors, currently becoming more conspicuous in Russia and some other countries, are militarist and machismo ideology [64], whereas promiscuity is sometimes seen as an attribute of "manliness". Within the context of sexual and reproductive coercion, contraception sabotage etc. [2], the following citation seems to be suitable as a concluding note: "It 
is not these men who are monstrous; rather, it is the society that has defined them and taught them to define themselves as a consequence of their gender" [65]. In other words, the wrongly understood idea of manliness may directly or indirectly justify the irresponsible sexual behavior [66].

\section{References}

1. Muzhanovskii EB, Fartushnyi AF, Sukhin AP, Sadov Al (1992) The detection of abortion agents in biological material. Sud Med Ekspert 35: 24-28.

2. Jargin SV (2016) Reliability of surveys on alcohol consumption, sexual coercion and contraception J Addiction Prevention 4: 5 .

3. Jargin S (2015) Memoirs and Selected Articles. Kindle eBook.

4. Jargin SV (2012) About the treatment of gonorrhea in the former Soviet Union. Dermatol Pract Concept 2: 12

5. Jargin SV (2016) Letter to the Editor: Treatment of gonorrhea in Russia: recent history. Global J Dermatol Venereol 4: 1-5.

6. Popov AA, Visser AP, Ketting E (1993) Contraceptive knowledge, attitudes and practice in Russia during the 1980s. Stud Fam Plann 24: 227-235.

7. Jargin S (2009) Overpopulation and modern ethics. S Afr Med J 99: 572-573.

8. (2013) World Abortion Policies. United Nations

9. Perlman FJ (2010) Drinking in transition: trends in alcohol consumption in Russia 1994-2004. BMC Public Health 10: 691.

10. Radaev $V$ (2015) Impact of a new alcohol policy on homemade alcohol consumption and sales in Russia. Alcohol Alcohol 50: 365-372.

11. Shuper PA, Neuman M, Kanteres F, Baliunas D, Joharchi N, Rehm et al. (2010) Causal considerations on alcohol and HIVIAIDS - a systematic review. Alcohol Alcohol 45: 159-166.

12. Lan CW, Scott-Sheldon LA, Carey KB, Johnson BT, Carey MP (2017) Prevalence of alcohol use, sexual risk behavior, and HIV among Russians in high-risk settings: a systematic review and meta-analysis. Int J Behav Med 24: $180-190$.

13. Salameh P, Salame J, Waked M, Barbour B, Zeidan N, et al. (2014) Risk perception, motives and behaviours in university students. Int $\mathrm{J}$ Adolesc Youth 19: 279-292.

14. Abdala N, Zhan W, Shaboltas AV, Skochilov RV, Kozlov AP, et al. (2011) Correlates of abortions and condom use among high risk women attending an STD clinic in St. Petersburg, Russia. Reprod Health 8: 28.

15. Krupitsky EM, Horton NJ,Williams EC, Lioznov D, Kuznetsova M, et al. (2005) Alcohol use and HIV risk behaviors among HIV-infected hospitalized patients in St. Petersburg, Russia. Drug Alcohol Depend 79: 251-256.

16. Boden JM, Fergusson DM, Horwood LJ (2011) Alcohol and STI risk: evidence from a New Zealand longitudinal birth cohort. Drug Alcohol Depend 113: 200

17. Weinhardt LS, Carey MP (2000) Does alcohol lead to sexual risk behavior? Findings from event-level research. Annu Rev Sex Res 11: 125-157

18. Jonas K, Crutzen R, van den Borne B, Sewpaul R, Reddy P (2016) Teenage pregnancy rates and associations with other health risk behaviours: a threewave cross-sectional study among South African school-going adolescents. Reprod Health 13: 50.

19. Davis KC, Kiekel PA, Schraufnagel TJ, Norris J, George WH, et al. (2012) Men's alcohol intoxication and condom use during sexual assault perpetration. J Interpers Violence 27: 2790-2806.

20. Tumwesigye NM, Ingham R, Holmes D (2013) Condom use at first and latest sexual events among young people: evidence from a rural and peri-urban setting in Uganda. Afr Health Sci 13: 407-414.

21. Latimer J, Fleckman J, Wallace M, Rountree M, Theall K (2017) The influence of violence victimization on sexual health behaviors and outcomes. AIDS Patient Care STDS 31: 237-244.
22. Fromme K, D'Amico EJ, Katz EC (1999) Intoxicated sexual risk taking: an expectancy or cognitive impairment explanation? J Stud Alcohol 60: 54-63.

23. Fromme K, Katz E, D’Amico E (1997) Eects of alcohol intoxication on the perceived consequences of risk taking. Exp Clin Psychopharmacol 5: 14-23.

24. Testa M, Livingston JA, Collins RL (2000) The role of women's alcohol consumption in evaluation of vulnerability to sexual aggression. Exp Clin Psychopharmacol 8: 185-191.

25. Davis KC, Stoner SA, Norris J, George WH, Masters NT (2009) Women's awareness of and discomfort with sexual assault cues: eects of alcohol consumption and relationship type. Violence Against Women 15: 1106-1125.

26. Steele CM, Josephs RA (1990) Alcohol myopia. Its prized and dangerous effects. Am Psychol 45: 921-933.

27. Abbey A (1991) Acquaintance rape and alcohol consumption on college campuses: how are they linked? J Am Coll Health 39: 165-169.

28. Jargin SV (2017) Popular alcoholic beverages in Russia with specia reference to quality and toxicity. J Addiction Prevention 5: 6 .

29. Parks KA, Collins RL, Derrick JL (2012) The influence of marijuana and alcohol use on condom use behavior: findings from a sample of young adult female bar drinkers. Psychol Addict Behav 26: 888-894.

30. Rehm J, Shield KD, Joharchi N, Shuper PA (2012) Alcohol consumption and the intention to engage in unprotected sex: systematic review and metaanalysis of experimental studies. Addiction 107: 51-59.

31. Sarkar NN (2008) Barriers to condom use. Eur J Contracept Reprod Health Care 13: 114-122.

32. Eaton LA, Cain DN, Pitpitan EV, Carey KB, Carey MP, et al. (2014) Exploring the relationships among food insecurity, alcohol use, and sexual risk taking among men and women living in South African townships. J Prim Prev 35: 255-265.

33. Howells NL, Orcutt HK (2014) Diary study of sexual risk taking, alcohol use, and strategies for reducingnegative aect infemale college students. J Stud Alcohol Drugs 75: 399-403.

34. Leigh BC, Stall R (1993) Substance use and risky sexual behavior for exposure to HIV. Issues in methodology, interpretation, and prevention. Am Psychol 48: 1035-1045

35. Medic A, Dzelalija B, Kozul K, Novosel IP, Dijanic T (2014) Risk factors influencing non-use of condoms at sexual relations in populations under heightened risk. Coll Antropol 38: 895-900.

36. Untied AS, OrchowskiLM, LazarV(2013)Collegemen'sandwomen'srespective perceptions of risk to perpetrate or experience sexual assault: the role of alcohol use and expectancies. Violence against Women 19: 903-923.

37. Johnson HL, Albery IP, Frings D, Moss AC (2018) STI-protective self-efficacy and binge drinking in a sample of university students in the United Kingdom. Sex Reprod Healthc 17: 19-25.

38. Courtney KE, Polich J (2009) Binge drinking in young adults: Data, definitions, and determinants. Psychol Bull 135: 142-156.

39. Quemada JI, Sánchez-Cubillo I, Muñoz-Céspedes JM (2007) Organic personality disorder: conceptual review and research strategies. Actas Esp Psiquiatr 35: 115-121.

40. Torregrossa MM, Quinn JJ, Taylor JR (2008) Impulsivity, compulsivity, and habit: the role of orbitofrontal cortex revisited. Biol Psychiatry 63: 253-255.

41. Jargin S (2016) Questionable information on poisonings by alcohol surrogates. Interdiscip Toxicol 9: 83-84.

42. MacDonald TK, Fong GT, Zanna MP, Martineau AM (2000) Alcohol myopia and condom use: can alcohol intoxication be associated with more prudent behavior? J Pers Soc Psychol 78: 605-619.

43. Davis KC, Masters NT, Eakins D, Danube CL, George WH, et al. (2014) Alcohol intoxication and condom use self-efficacy effects on women's condom use intentions. Addict Behav 39: 153-158.

44. Cooper ML (2002) Alcohol use and risky sexual behavior among college 
students and youth: evaluating the evidence. J Stud Alcohol Suppl 14: 101 117

45. Weir BW, Latkin CA (2015) Alcohol, intercourse, and condom use among women recently involved in the criminal justice system: Findings from integrated global-frequency and event-level methods. AIDS Behav 19: 10481060.

46. Raj A, Cheng DM, Krupitsky EM, Levenson S, Egorova VY, et al. (2009) Binge drinking and unsafe sex: a study of narcology hospital patients from St. Petersburg, Russia. Subst Abus 30: 213-222.

47. Wang SC, Lui JHL, Vega G, Waldrop M, Garris J (2018) The moderating effect of alcohol use on protective and risky sex behaviors among college students in the Southeast United States. J Am Coll Health 1-7.

48. Bryan AEB, Norris J, Abdallah DA, Zawacki T, Morrison DM, et al. (2017) Condom-insistence conflict in women's alcohol-involved sexual encounters with a new male partner. Psychol Women Q 41: 100-113.

49. Brown JL, Gause NK, Northern N (2016) The association between alcohol and sexual risk behaviors among college students: a review. Curr Addict Rep 3: 349-355.

50. Brown JL, DiClemente RJ, Sales JM, Rose ES, Gause NK, et al. (2016) Alcohol use, partner characteristics, and condom use among HIV-infected Russian women: an event-level study. J Stud Alcohol Drugs 77: 968-973.

51. Gallo MF, Warner L, Bell AJ, Bukusi EA, Sharma A, et al. (2011) Determinants of condom use among female sex workers in Kenya: a case-crossover analysis. J Womens Health (Larchmt) 20: 733-738.

52. Xiao Z, Palmgreen P, Zimmerman R, Noar S (2010) Adapting and applying a multiple domain model of condom use to Chinese college students. AIDS Care 22: 332-338.

53. Matovu JK, Ssebadduka NB (2013) Knowledge, attitudes \& barriers to condom use among female sex workers and truck drivers in Uganda: a mixedmethods study. Afr Health Sci 13: 1027-1033.

54. Faye A, Faye MD, Leye MM, Diongue M, Niang K, et al. (2014) Study of determinants of unprotected sex in sailors of the Senegalese merchant navy. Bull Soc Pathol Exot 107: 115-120.
55. Fentahun N, Mamo A (2014) Risky sexual behaviors and associated factors among male and female students in Jimma Zone preparatory schools, South West Ethiopia: comparative study. Ethiop J Health Sci 24: 59-68.

56. Papas RK, Gakinya BN, Mwaniki MM, Wu XK, Lee H, et al. (2018) Associations with unprotected sexual behavior among HIV-infected drinkers in Western Kenya. AIDS Behav.

57. Guo C, Wen X, Li N, Wang Z, Chen G, et al. (2017) Is cigarette and alcohol use associated with high-risk sexual behaviors among youth in China? J Sex Med 14: 659-665.

58. Yi S, Tuot S, Chhoun P, Pal K, Ngin C, et al. (2017) Sex with sweethearts: Exploring factors associated with inconsistent condom use among unmarried female entertainment workers in Cambodia. BMC Infect Dis 17: 20.

59. Kanda L, Mash R (2018) Reasons for inconsistent condom use by young adults in Mahalapye, Botswana. Afr J Prim Health Care Fam Med 10: e1-e7.

60. Khan MR, Berger AT, Wells BE, Cleland CM (2012) Longitudinal associations between adolescent alcohol use and adulthood sexual risk behavior and sexually transmitted infection in the United States: assessment of differences by race. Am J Public Health 102: 867-876.

61. Wand H, Bryant J, Worth H, Pitts M, Kaldor JM, et al. (2018) Low education levels are associated with early age of sexual debut, drug use and risky sexual behaviours among young Indigenous Australians. Sex Health 15: 6875.

62. Hines AM, Caetano R (1998) Alcohol and AIDS-related sexual behavior among Hispanics: acculturation and gender differences. AIDS Educ Prev 10: 533-547.

63. Bohora S, Chaffin M, Shaboltas A, Bonner B, Isurina G, et al. (2017) Latent class analysis of HIV risk behaviors among Russian women at risk for alcoholexposed pregnancies. AIDS Behav 21(Suppl 2): 243-252.

64. Jargin SV (2016) Nuclear facilities and nuclear weapons as a guarantee of peace. J Def Manag 6: 146.

65. Butler S (1979) Conspiracy of silence: The trauma of incest. Bantam, Toronto, Canada pp. 215

66. Jargin SV (2018) The male to female ratio at birth: The role of femicide and other mechanisms. Early Hum Dev 123: 33-34. 